\title{
The Congenital Disorders of Glycosylation: A Multifaceted Group of Syndromes
}

\author{
Erik A. Eklund*广 and Hudson H. Freeze ${ }^{\dagger}$ \\ * Department of Cell and Molecular Biology, Lund University, Lund, Sweden; and ${ }^{\dagger}$ Program for Glycobiology and Carbohydrate \\ Chemistry, Burnham Institute for Medical Research, La Jolla, California 92037
}

Summary: The congenital disorders of glycosylation (CDG) are a rapidly expanding group of metabolic syndromes with a wide symptomatology and severity. They all stem from deficient $\mathrm{N}$-glycosylation of proteins. To date the group contains 18 different subtypes: 12 of Type I (disrupted synthesis of the lipid-linked oligosaccharide precursor) and 6 of Type II (malfunctioning trimming/processing of the protein-bound oligosaccharide). Main features of CDG involve psychomotor retardation; ataxia; seizures; retinopathy; liver fibrosis; coagulopathies; failure to thrive; dysmorphic features, includ- ing inverted nipples and subcutaneous fat pads; and strabismus. No treatment currently is available for the vast majority of these syndromes (CDG-Ib and CDG-IIc are exceptions), even though attempts to synthesize drugs for the most common subtype, CDG-Ia, have been made. In this review we will discuss the individual syndromes, with focus on their neuronal involvement, available and possible treatments, and future directions. Key Words: N-glycosylation, CDG, mannose, synthetic compounds, brain glycosylation, ataxia, cerebellar hypoplasia, cerebellar hypoplasia, seizures.

\section{N-GLYCOSYLATION}

A large portion of the proteins in the human body carry modifications and one of the most common is glycanation. Addition of carbohydrates to proteins requires complex machinery and demands coordinated expression of hundreds of genes. In fact, around $1 \%$ of the expressed human genome is predicted to encode proteins involved in the glycosylation process. ${ }^{1}$ Protein glycosylation exists in two major variants, $\mathrm{N}$ - and O-linked. ${ }^{2}$ The $\mathrm{N}$-linked glycosylation occurs cotranslationally and is initiated in the endoplasmic reticulum. A precursor oligosaccharide, containing 14 residues ( $2 \mathrm{~N}$-acetyl glucosamine (GlcNAc), 9 mannose (Man), and 3 glucose (Glc) residues), is first built on a dolichol-phosphate (Dol-P; forming the lipid-linked oligosaccharide (LLO)) anchor and then transferred to consensus sequence asparagine residues in the nascent acceptor proteins (FIG. 1). The oligosaccharide is then trimmed by various glycosidases, a process vital for protein folding and quality control. In the Golgi apparatus, the oligosaccharides may be further trimmed and modified (FIG. 2), creating enor-

Address correspondence and reprint requests to Hudson H. Freeze, Ph.D., Burnham Institute for Medical Research, 10901 North Torrey Pines Road, La Jolla, CA 92037. E-mail: Hudson@burnham.org. mous variation among the different types of structures found. This gives rise to three distinct groups of $\mathrm{N}$ glycans: 1) high-mannose, 2) hybrids, and 3) complex types (FIG. 2). ${ }^{3}$ The $\mathrm{N}$-linked glycans have been proven to take part in processes throughout the "life" of proteins, from their initial folding and trafficking to their function and regulation of their degradation. ${ }^{2,4}$ It is therefore not surprising that deficiencies in the formation of $\mathrm{N}$-glycans cause severe syndromes with multiple organ involvement. $^{5-7}$

\section{CONGENITAL DISORDERS OF GLYCOSYLATION}

\section{Overview}

Since the initial report in $1980,{ }^{8}$ the field of glycosylation-related congenital syndromes has expanded enormously. Several syndromes stem from mutations in genes forming glycan structures other than $\mathrm{N}$-linked ones, such as the hereditary multiple exostoses (a defect in heparan sulfate biosynthesis), some muscular dystrophies (e.g., muscle-eye-brain disease and Walker-Warburg syndrome), and a type of progeria (deficiency of galactosyltransferase-I). Also, recently, it was shown that familial tumoral calcinosis is caused by mutations in the initiation of O-glycosylation probably on FGF-23. ${ }^{9}$ This 


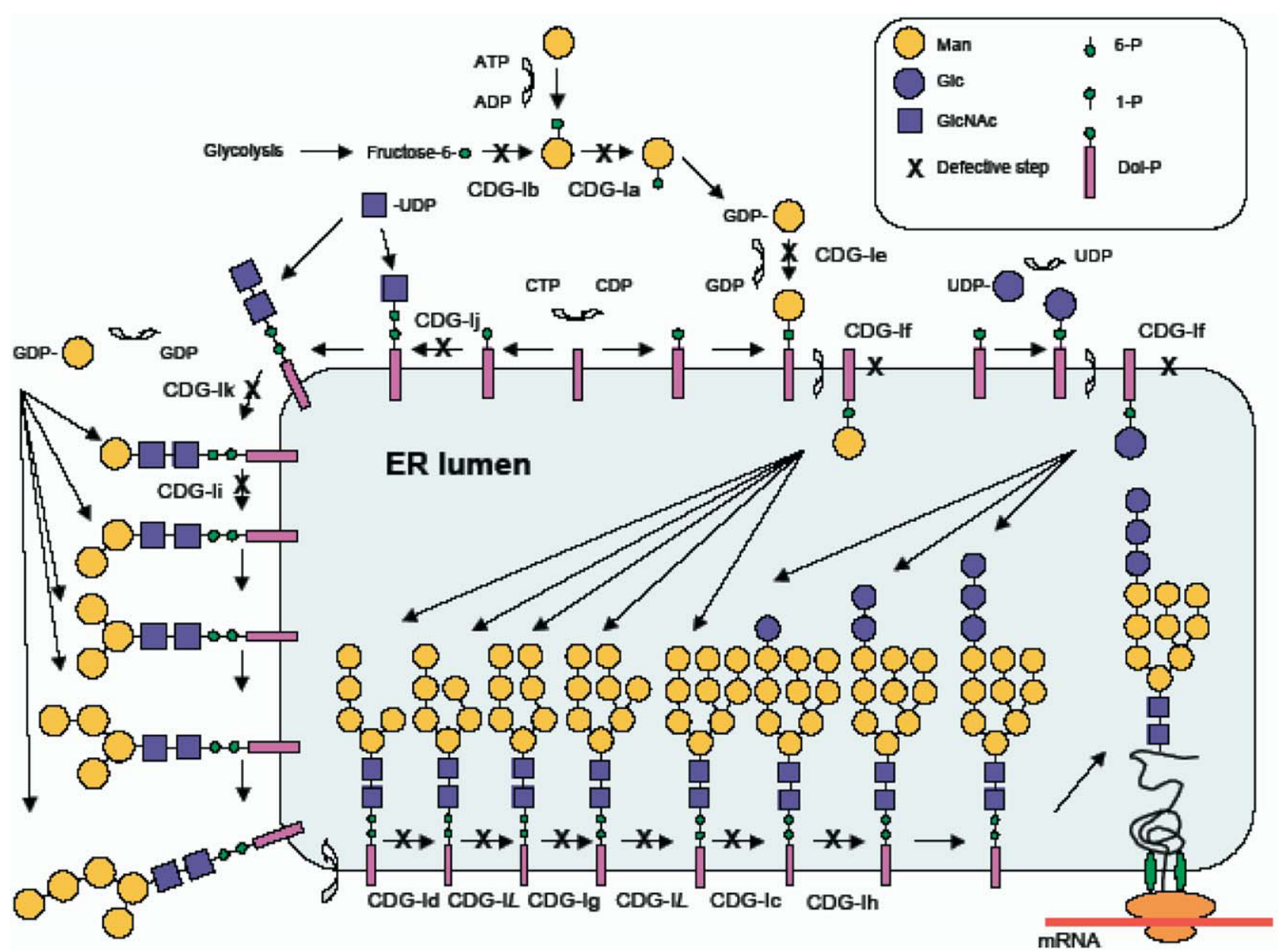

FIG. 1. Biosynthetic scheme of the lipid-linked oligosaccharide (LLO) precursor for N-linked glycosylation. The LLO synthesis is a complex process, both located in the cytosol and the endoplasmic reticulum (ER). Monosaccharides are first activated to their corresponding nucleotide sugars and then transferred to the growing LLO chain or to the polyisoprenoid dolichol-phosphate. A hepta-oligosaccharide $\left(\mathrm{Man}_{5} \mathrm{GlcNAc}_{2}-\mathrm{P}-\mathrm{P}-\mathrm{Dol}\right)$ is formed on the cytosolic side of the ER using nucleotide sugars as donors. This structure is translocated to the inside and the mature LLO $\left(\mathrm{Glc}_{3} \mathrm{Man}_{9} \mathrm{GlcNAc}_{2}-\mathrm{P}-\mathrm{P}-\mathrm{Dol}\right)$ is completed using Dol-P-Man and Dol-P-Glc as substrates. The oligosaccharide is thereafter transferred to asparagine residues in the acceptor proteins. Steps that have been found defective in different forms of CDG Type I are indicated. In the biosynthetic pathway of GDP-Man, direct phosphorylation of Man by hexokinase is included, the pathway used to treat CDG-lb.

review will, however, focus on disorders caused by a defective synthesis of $\mathrm{N}$-glycans, the so called congenital disorders of glycosylation (CDGs). The CDGs were earlier known as the carbohydrate-deficient glycoprotein syndromes (CDGS) as their diagnosis is based on the finding of underglycosylated transferrin. The CDGs can be divided into two different types. In all of the CDG Type I defects, the underlying lesion disrupts the synthesis, or transfer, of the LLO precursor sugar chain for N-linked glycosylation (see above; FIG. 1); whereas all of the CDG Type II defects involve impaired trimming/ processing of the oligosaccharide when it is bound to its nascent protein (FIG. 2) ${ }^{6,7}$ Even though the number of genes involved in protein-bound oligosaccharide processing by far outnumber the ones involved in the LLO synthesis, most known CDG patients are of Type I. A combined arsenal of diagnostic tools, including enzy- matic assays and radiolabeling of LLOs, has made it relatively straightforward to resolve Type I defects; whereas finding the molecular background to CDG Type II has been more tedious and has required more advanced techniques. Today there are 12 known CDG Types $\mathrm{I}^{10-22}$ and 6 Types II. $^{23-28}$ Clinically, many symptoms are shared by several CDG subtypes-psychomotor retardation, ataxia, failure to thrive, dysmorphic features (including inverted nipples and subcutaneous fat pads), and coagulopathies-but there are also noticeable differences. Below follows a short description of each individual subtype.

\section{Identification of CDG patients}

When CDG is suspected as a differential diagnosis, a serum sample is analyzed for deficient transferrin glycosylation, either by isoelectric focusing, ${ }^{29}$ mass spectrom- 

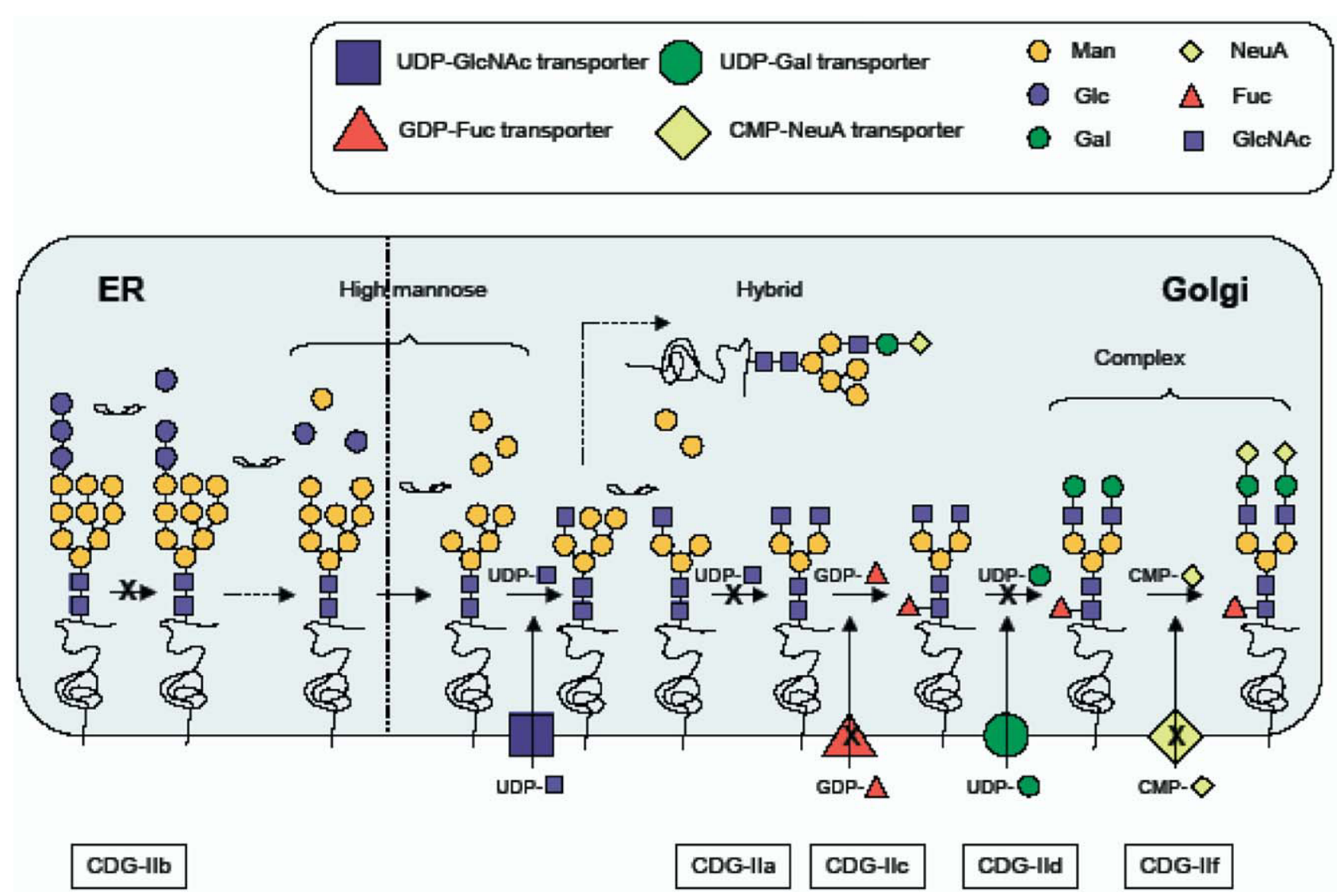

FIG. 2. Processing of protein-bound N-linked glycans. After the oligosaccharide has been transferred to the nascent protein, it can be trimmed and processed into a large variety of structures. Deficiencies in these steps constitute the CDG Type II syndromes. The three subclasses of $\mathrm{N}$-linked glycans, high mannose, hybrid and complex types, are indicated. Steps in nucleotide sugar transport into the Golgi are shared with O-linked glycosylation pathways, and therefore, in some of the CDG Type II syndromes, this type of glycosylation is affected as well.

etry, ${ }^{30}$ or other available methods. ${ }^{31,32}$ Transferrin normally carries two complex oligosaccharide chains, having a total of four sialic acid (NeuA) residues. In most CDG syndromes, hyposialylated (less than four NeuA) species are seen in a larger proportion than normal, which is diagnostic. Other metabolic causes of hyposialylation of transferrin however exist (e.g., galactosemia, ${ }^{33}$ hereditary fructosemia, ${ }^{34}$ and prolonged alcohol intake ${ }^{35}$ ) and have to be excluded. Also, a few of the known CDG subtypes do not have a pathological transferrin pattern (CDG-IIb, CDG-IIc, and CDG-IIf), showing that some Type II CDGs can fail to be detected if hyposialylation of transferrin is the only glycoanalysis performed. Other liver disorders, such as cirrhosis, show glycosylation changes ${ }^{36}$ but do not show up on the transferrin analysis. Since screening for CDG is a cheap, simple, and rapid analysis, we recommend that CDG is excluded in all undiagnosed patients with unrelated symptoms from at least two organs, especially in the presence of cerebellar hypoplasia, developmental delay, or coagulopathy.

\section{CDG-Ia (formerly known as CDGS-I)}

Most patients diagnosed with CDG belong to this group, and over 600 patients are known worldwide. The defective gene is $P M M 2,{ }^{22}$ encoding phosphomannomutase (PMM), the enzyme responsible for conversion of Man-6-phosphate $(\mathrm{M} 6 \mathrm{P}) \rightarrow$ Man-1-phosphate $\quad$ M1P). ${ }^{37}$ PMM deficiency leads to diminished production of GDP-Man and Dol-PMan, both essential precursors for LLO biosynthesis. The most common mutation is $\mathrm{R} 141 \mathrm{H}$, with a carrier frequency in a Caucasian population (Danish) of about $1 / 60 .^{38}$ The $\mathrm{R} 141 \mathrm{H}$ mutation gives rise to an enzyme with no activity and has never been found to be homozygous in a patient, indicating that some residual PMM activity is required for fetal survival. Diagnosis of CDG-Ia is made by a positive transferrin hypoglycosylation test followed by an enzymatic assay of PMM in either fibroblasts or white blood cells.

The first patients diagnosed with CDG-Ia were phenotypically rather alike, presenting with inverted nipples, subcutaneous fat pads, psychomotor retardation, ataxia due to cerebellar hypoplasia (or sometimes olivoponto- 
cerebellar hypoplasia $^{39}$ ), retinitis pigmentosa (progressing over time), and short stature, a phenotype still considered the "classical" presentation of CDG. Unfortunately, this is the ruling paradigm among clinicians not directly working with CDG patients, which effectively diminishes the number of patients screened for CDG. Today we know that CDG-Ia can present a wide spectrum of symptoms, ranging from only very mild retardation ${ }^{40-42}$; to hypoglycemia, ${ }^{43}$ gastrointestinal problems, ${ }^{44}$ or hypertrophic cardiomyopathy ${ }^{45}$ as leading symptoms; to profound psychomotor retardation, intractable seizures, and grave dysmorphisms in severely affected individuals. High residual PMM activity in fibroblasts may be a potential pitfall, as a patient may be considered normal upon analysis. ${ }^{40,41}$

Why most CDG patients develop neuronal problems is not fully known. The structures of N-linked glycans of the brain differ a lot from glycans of other organs and there are a multitude of unusual structures found in brain tissue. A specific feature of brain $\mathrm{N}$-glycoproteins is the presence of incompletely processed oligosaccharides, lacking terminal NeuA and galactose residues. Other prominent features involve core and outer arm fucosylated species, oligosaccharides with bisecting GlcNAc, and species with specifically bonded NeuA (reviewed by Albach et al. ${ }^{46}$ ). This plethora of unusual structures implies that a vast amount of processes during neurodevelopment require a specific structure and it is easily comprehended that lack or addition of a brain oligosaccharide is detrimental to the fine-tuned process of fetal brain development. However, very few of these structures have been proven to take part in the development of the brain. In a case description by Aronica et al., ${ }^{47}$ the brain of a CDG-Ia patient was studied. It was shown that the patient had a pronounced lack of Purkinje cells in the cerebellum, but it is unknown whether lack of a specific oligosaccharide structure accounts for this neuropathological finding. To study whether the glycosylation-related neuronal pathologies in CDG derive from errors in early development (i.e., being static) or whether there is a continuous process during life (i.e., being dynamic) is important in the context of potential neurotherapeutics, a matter that will be discussed more in depth later in this review.

\section{CDG-Ib}

CDG-Ib (around 20 known patients) is due to a deficiency in phosphomannose isomerase (PMI), the enzyme that catalyzes the formation of M6P from fructose-6phosphate. ${ }^{21}$ It is the only treatable CDG Type I syndrome (alimentary mannose; see below) and also differs from the other subtypes as the patients are mentally spared. The main features of this syndrome instead are failure to thrive, coagulopathy, protein-losing enteropathy, and hypoglycemia. A rapid diagnosis is of great importance since this is a potentially lethal disorder (severe hypoalbuminemia; massive bleedings) that has a simple and effective treatment. It is therefore vital that CDG-Ib is part of the differential diagnoses in patients with inexplicable coagulopathies, intestinal protein loss, or hypoglycemia. Diagnosis is done by an enzymatic analysis in cells from the patient.

\section{CDG-Ic}

CDG-Ic is the second most common CDG subtype with more than 20 known patients. It stems from a deficiency of the first glucosyltransferase that adds a Glc residue to the growing LLO chains, encoded by the gene $h A L G 6 .{ }^{20}$ The phenotype of this syndrome is usually milder than classical CDG-Ia, often with a spared cerebellum and minor psychomotor retardation. ${ }^{7}$ Why these patients experience milder symptoms is not completely known, but it seems that defects that occur relatively late in the LLO formation have a smaller impact on neurofunction, possibly because these chains are transferred to the proteins in a larger amount than shorter chains. Features such as low LDL, deficiency in coagulation factor $\mathrm{XI}$, and protein-losing enteropathy are often present and may persist into adolescence. ${ }^{48}$ The diagnosis of CDG-Ic is made by the detection of truncated LLOs, lacking Glc, after a positive transferrin hypoglycosylation test has been performed.

\section{CDG-Id}

This is a very severe subtype of CDG, often with multiple facial dysmorphic features, intractable seizures, pronounced mental retardation, and optic nerve atrophy. ${ }^{49-51}$ The defective gene is $h A L G 3$, encoding the enzyme that catalyzes the first Dol-P-Man-dependent step in LLO formation, addition of the sixth mannosyl residue to the growing LLO chain. Only six patients have been described and the diagnosis is based on a pathological LLO pattern together with mutational analysis.

\section{CDG-Ie}

This syndrome stems from mutations in the gene (DPM1) that encodes the catalytic domain of Dol-P-Man synthase. ${ }^{18}$ It is very severe and is characterized by pronounced psychomotor retardation, muscular hypotonia, and often blindness and facial dysmorphisms such as hypertelorism. The children sometimes have normal birth weight, length, and head circumference, but microcephaly is characteristic later. ${ }^{18,52,53}$ Five patients have been published to date, and the diagnosis is based on enzymatic analysis of Dol-P-Man synthase and a defective LLO pattern with accumulation of $\mathrm{Man}_{5} \mathrm{GlcNAc}_{2}$ structures.

\section{CDG-If}

In CDG-If, the underlying defect (MPDU1) encodes a protein for which the function is not fully understood but 
is involved in the utilization of Dol-P-Man and Dol-PGlc. Phenotypically it resembles CDG-Id and -Ie; in addition, interestingly, two patients presented with ichthyosis. ${ }^{16,17}$ To date there are six known patients and the diagnosis is based on a pathological LLO pattern (accumulation of $\mathrm{Man}_{5} \mathrm{GlcNAc}_{2}$ and $\mathrm{Man}_{9} \mathrm{GlcNAc}_{2}$ structures) and genetic analysis.

\section{CDG-Ig}

Deficiency of the mannosyltransferase that catalyzes the addition of the eighth Man residue to the growing LLO chain (encoded by $h A L G 12$ ) is the molecular etiology to this subtype. ${ }^{15}$ The patients present with psychomotor retardation, hypotonia, and often inverted nipples and subcutaneous fat pads. Interestingly, many of these patients are more prone to infection and show a deficiency in IgG. Of the known male patients, all have shown genital hypoplasia, but there is no distinct molecular explanation to this finding. ${ }^{54}$ In this group the variation of severity is considerable and very active intervention with physical, speech, and occupational therapy has been suggested to be clearly beneficial. ${ }^{54}$ There are ten known cases, and the diagnosis is based on accumulation of truncated LLO ( $\mathrm{Man}_{7} \mathrm{GlcNAc}_{2}$ structures) and genetic analysis.

\section{CDG-Ih}

Along with CDG-Ib, this is the only CDG subtype that can present without noticeable neuronal involvement. It stems from mutations in $h A L G 8$, encoding the second glucosyltransferase in the LLO synthetic pathway. ${ }^{14}$ The patients often present with a severe syndrome involving the liver, the intestine, and the kidneys, and an early, fatal outcome is often seen (coagulopathies, protein-losing enteropathy, kidney failure). ${ }^{55}$ The lack of severe symptoms from the brain can be explained, in most patients, by the fact that they succumbed before reaching an age at which they could be properly monitored. ${ }^{55,56}$ However, the first known case was 3 years at the time of diagnosis and no neurological findings were present. ${ }^{14}$ Possibly the lack of CNS symptoms in this case can be explained by the relatively low underglycosylation $\left(\mathrm{Glc}_{1} \mathrm{Man}_{9} \mathrm{GlcNAc}_{2}\right.$ structures are transferred relatively well to proteins), whereas the presence of a structure derived from this precursor may be involved in the kidney pathology, not seen commonly in other CDG subtypes. A pathological LLO pattern (accumulating $\mathrm{Man}_{9} \mathrm{GlcNAc}_{2}$ and $\mathrm{Glc}_{1} \mathrm{Man}_{9} \mathrm{GlcNAc}_{2}$ structures), along with genetic analysis, diagnoses CDG-Ih, and there are five known cases to date.

\section{CDG-Ii}

The only patient published with this syndrome was normal at birth, but during the first year developed hypomyelination, mental retardation, seizures, hepatomegaly with coagulation deficiencies, and coloboma of the iris. ${ }^{13}$ The defective gene was $h A L G 2$, which encodes the second mannosyltransferase in the LLO pathway. Diagnosis was based on the abnormal LLO pattern, an enzymatic assay, genetic analysis, and complementation of a yeast strain.

\section{CDG-Ij}

There is only one known case with this defect. The patient presented with mental retardation, microcephaly, intractable seizures, muscular hypotonia, and esotropia. ${ }^{12}$ The defective gene (DPAGTI) encodes a GlcNAc transferase, catalyzing the addition of the first GlcNAc to the growing LLO chain. The diagnosis was based on LLO analysis (low amounts of LLO formed), enzymatic assays, and genetic analysis.

\section{CDG-Ik}

This is an extremely severe syndrome and only one of four known patients survived into the second year. ${ }^{11,57,58}$ All patients showed intractable seizures, and hypotonia, cerebral atrophy, visual impairment, and coagulopathy were prominent features. One patient developed nephrotic syndrome and hypogammaglobulinemia, ${ }^{58}$ whereas another had grave dysmorphic features and cardiomyopathy, ${ }^{57}$ showing the large variability within the CDG subtypes. CDG-Ik is due to a deficiency in the first mannosyltransferase (encoded by $h A L G l$ ) in the LLO biosynthetic pathway and is diagnosed using LLO analysis of short species, ${ }^{59}$ enzymatic assays, and genetic analysis.

\section{CDG-IL}

CDG-IL stems from a deficiency in a mannosyltransferase that catalyzes the addition of both the seventh and the ninth mannose residue onto the growing LLO chain. It is encoded by $h A L G 9$ and there are two known patients to date. ${ }^{10,60}$ Both had severe brain abnormalities, including microcephaly, ${ }^{10}$ diffuse brain atrophy, cerebellar hypoplasia, delayed myelination, and seizures. ${ }^{60}$ One patient also showed failure to thrive, cystic renal disease, hepatosplenomegaly, pericardial effusion, and inverted nipples. ${ }^{60}$ Their diagnoses were based on a pathological LLO pattern (accumulating $\mathrm{Man}_{6} \mathrm{GlcNAc}_{2}$ and $\mathrm{Man}_{8} \mathrm{GlcNAc}_{7}$ structures) and genetic analysis.

\section{CDG-IIa (formerly known as CDGS-II)}

This syndrome is caused by a deficiency in the GlcNAc transferase-II (encoded by MGAT2), ${ }^{61}$ an enzyme involved in the formation of complex-type oligosaccharide. ${ }^{62}$ Four patients are known, ${ }^{7}$ and there is also an accurate phenocopy animal model at hand. ${ }^{63}$ There is a marked psychomotor retardation compared to CDG-Ia, but no peripheral neuropathy and normal deep-tendon reflexes. The patients display facial dysmorphisms and develop muscular hypotonia. Seizures have been described in this subset. Concerning coagulation, in con- 
trast to CDG-Ia patients, who are usually prothrombotic, CDG-IIa patients are at the anticoagulant side of the spectrum. A possible explanation of this notion is that platelets from CDG-Ia patients have an enhanced nonspecific platelet interaction, whereas CDG-IIa platelets are deficient in glycoprotein Ib reactivity with the vessel walls. ${ }^{64}$ Diagnosis of CDG-IIa is based on oligosaccharide structure analysis and enzymatic assays.

\section{CDG-IIb}

This syndrome is due to a deficient first processing step of the protein-bound oligosaccharide, a mal-functioning $\alpha$-glucosidase-I (encoded by GCS 1 ) ${ }^{27}$ Only one patient has been described, a consanguineous girl with generalized hypotonia, seizures, multiple dysmorphic features, hepatomegaly, feeding problems, and hypoventilation. The outcome was fatal at 74 days. Diagnosis was based on the finding of a tetrasaccharide (Man- $\mathrm{Glc}_{3}$ ) in the urine and a consecutive analysis of the $\alpha$-glucosidase-I activity.

\section{CDG-IIc (also known as leukocyte adhesion deficiency type II (LADII))}

CDG-IIc is caused by mutations in the GDP-fucose (Fuc) transporter (encoded by FUCT1). ${ }^{26}$ This syndrome is characterized by nonfucosylated oligosaccharides and presents with severe mental retardation and immunodeficiency due to an adhesion defect of the leukocytes (probably due to absence of $\alpha$-1,3-fucosylated sialylLewis ${ }^{x}$ selectin ligands). ${ }^{65}$ Two patients have responded well to alimentary addition of Fuc, whereas others were nonresponders (see below). Diagnosis is based on oligosaccharide and mutational analyses.

\section{CDG-IId}

Mutations in B4GALT1 cause CDG-IId, ${ }^{25}$ a deficiency of a galactosyltransferase involved in the formation of sialylated complex type oligosaccharides. ${ }^{66}$ One patient has been described so far, suffering from a syndrome involving muscular hypotonia, mild developmental delay, coagulopathy, and myopathy. He also had a DandyWalker malformation with macrocephalus and progressive hydrocephalus. It was speculated that this malformation was coincidental, but it is noteworthy that a Dandy-Walker malformation also has been described in a CDG-Id patient. ${ }^{51}$ Diagnosis was based on oligosaccharide and mutational analysis.

\section{CDG-IIe}

CDG-IIe differs from other types of CDGs since the molecular etiology is caused by mutations in a protein not directly involved in glycosylation, but rather in Golgi function. ${ }^{24}$ It stems from a deficiency in the conserved oligomeric Golgi complex-7 (COG7; encoded by COG7), which is a subunit of COG, a complex involved in inter- and intra-Golgi trafficking of proteins. ${ }^{67}$ Two consanguineous siblings were described with a syndrome characterized by severe dysmorphic features, hypotonia, and progressive, fatal liver disease. ${ }^{68}$ The diagnosis was facilitated by the presence of characterized Chinese hamster ovary cell mutants with a similar glycosylation phenotype (involvement in both $\mathrm{N}-$, O-, and sphingolipid glycosylation) ${ }^{69}$ and was based on thorough oligosaccharide characterization and mutational analysis. ${ }^{24}$ Other COG defects (COG1 and COG8) have recently been discovered in patients and were published in an abstract, ${ }^{70}$ but they have no subtype assignation.

\section{CDG-IIf}

This syndrome is caused by a deficiency in the CMPsialic acid transporter (encoded by SLC35AI), and, in the only patient known, ${ }^{23,71}$ caused a fatal bleeding disorder with severe thrombocytopenia and giant platelets. A characteristic deficiency in sialylated leukocyte oligosaccharides was seen.

\section{TREATMENT OF CDG}

\section{Treatable CDGs}

To date there are only therapies available for two of the CDG subtypes, CDG-Ib and CDG-IIc. In CDG-Ib, alimentary addition $\left(300-750 \mathrm{mg} / \mathrm{kg} / \mathrm{day}^{21,72}\right)$ of Man bypasses the defective step (conversion of F6P to M6P) by allowing for formation of M6P via the action of hexokinase. These children, whose main symptoms are failure to thrive, coagulopathies, protein-losing enteropathy, and liver fibrosis, show remarkable improvement when the therapy is initiated..$^{21,72,73}$ However, there are no detectable neuronal abnormalities in CDG-Ib. This is probably due to the fact that the mother's serum Man concentration is high enough to supply an "endogenous therapy" during the fetal life. CDG-IIc, also known as leukocyte adhesion deficiency type II (LAD-II), stems from a defective membrane transport of GDP-L-Fuc. ${ }^{26}$ Apart from high blood leukocyte counts and recurrent bacterial infections, these patients suffer from mental retardation, have a short stature, and characteristic facial abnormities. Alimentary supplementation with Fuc corrected the immunological defect in one patient and also improved the neurological symptoms. ${ }^{65}$ However, in another set of three CDG-IIc patients, Fuc supplementation was ineffective. ${ }^{74}$ This discrepancy in outcome was suggested to be the difference in mutations, one affecting the $K_{\mathrm{m}}$ of the GDP-Fuc transporter, hence being sensitive to an increased Fuc pool, and one affecting the GDP-Fuc transport $V_{\max }$, rendering it insensitive to Fuc treatment. ${ }^{75}$ An attempt to treat CDG-IIc children with Fuc is therefore recommended $(490 \mathrm{mg} / \mathrm{kg} \times 5$, in the reported successful case ${ }^{65}$ ) since, even though they may be insensitive to the treatment, no adverse affects were noted. 


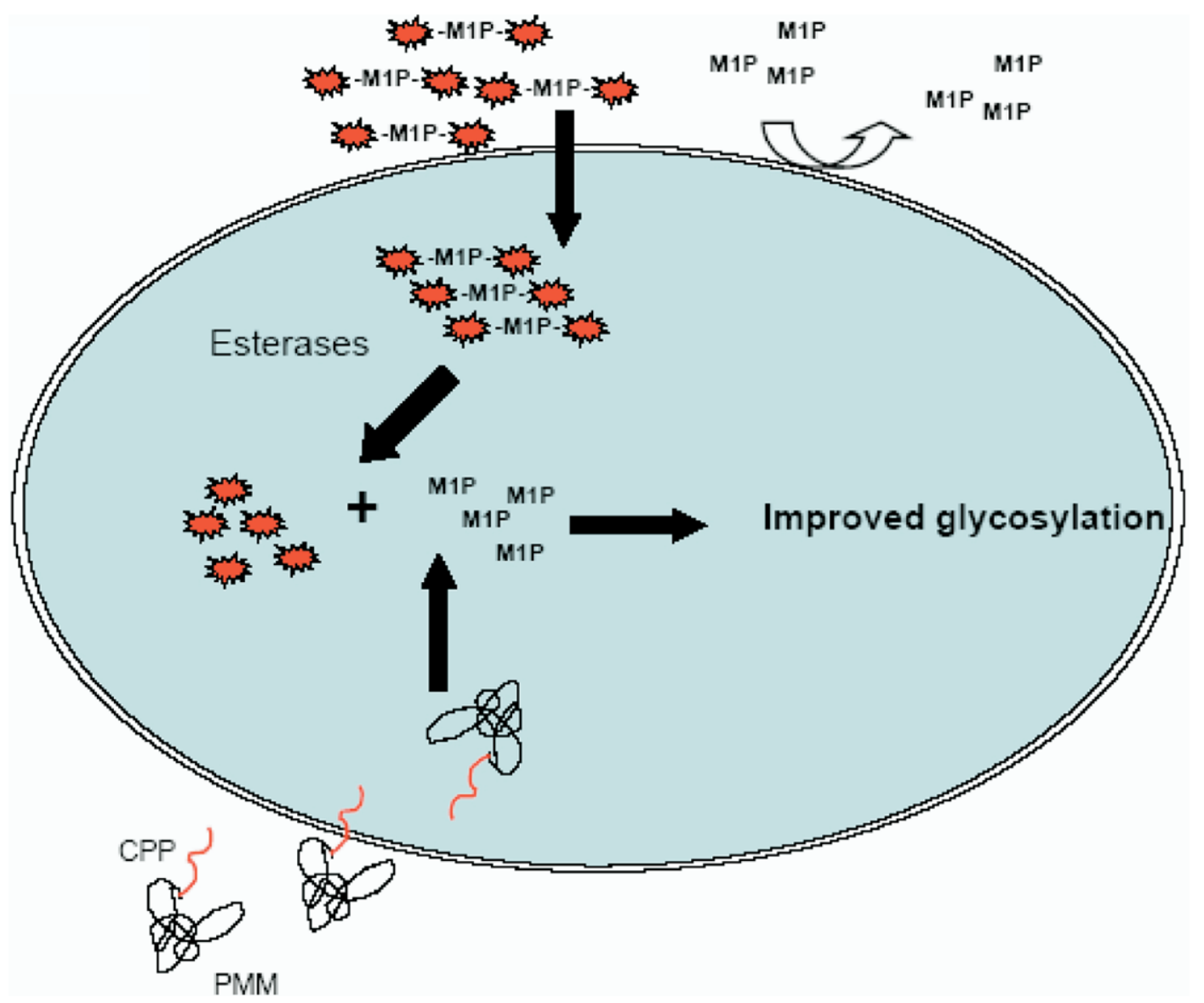

FIG. 3. Theoretical ways to treat CDG-la. Free M1P is not transported over the cell membrane nor does it diffuse. To complement the low M1P concentration in CDG-la patients, other possible modes of delivery must be explored. Covering the hydrophilic phosphate and hydroxyl groups with hydrophobic protection groups has been tested in cell culture systems ${ }^{80-82}$ and increase the intracellular concentration of M1P. After penetrating the cell membrane, the compounds are hydrolyzed by intracellular esterases (or self-decompose), yielding free M1P and free protecting groups. The M1P can then replenish the defective glycosylation. Another theoretical strategy is to express PMM with a terminally linked cell-penetrating peptide (CPP), allowing its uptake over the cell membrane. If the PMM retains its catalytic activity, the M1P pool would then be recovered upon entry.

\section{Possible therapeutics in CDG}

Man treatment has also been tried in CDG-Ia patients, as CDG-Ia fibroblasts adopt a normal LLO phenotype when incubated with high Man concentrations in the culture medium. ${ }^{76}$ This was, however, a clinical setback, as no measurable clinical parameters were affected in these children during treatment. ${ }^{77-79}$ The probable explanation is that PMI, the enzyme defective in CDG-Ib, efficiently converts the M6P to fructose-6-phosphate, preventing an increase in the M6P pool, hindering a higher biosynthesis of GDP-Man and Dol-P-Man. Direct alimentary supplementation with M1P is not possible since it does not diffuse, and is not transported, across the cell membrane. To overcome this issue, several groups, including ours, have attempted to chemically synthesize cell-permeable M1P compounds that would be converted to free M1P upon cell entry (FIG. 3) ${ }^{80-82}$ We choose to make M1P with acetoxymethylated phosphates and ethylcarbonate or acetyl groups protecting the $\mathrm{OH}$ groups. ${ }^{80}$ In cell culture, these compounds correct the LLO phe- notype in several CDG type fibroblasts at a lower concentration than Man and also compete with radiolabeled Man in a glycosylation assay. ${ }^{80}$ This validates the theoretical concept. However, several other issues have to be addressed. All compounds synthesized to date are far too unstable to be useful in the clinic. The best compound has a half-life in serum of about $2.5 \mathrm{~min}$ and would require continuous supplementation of large amounts of compound to maintain therapeutic levels. This is further confounded by the relatively high concentrations needed to get sufficient uptake through the cell membrane. Today's best compounds must be added to the medium at a concentration of around $100 \mu \mathrm{M}$ to be effective, 10-fold less would be desirable for a therapeutic. A third issue is the toxicity of these compounds. The most effective compound synthesized so far shows negative effects on protein synthesis and cell viability at concentrations above $100 \mu \mathrm{M}$, i.e., in the same range as its therapeutic interval. More M1P compounds therefore need to be made and tested. Using less toxic blocking groups, e.g., 
based on positively changed amino acids or catecholamines, is a potential area to explore in the future; liposomal delivery of free M1P is another. Apart from the labor-intensive synthesis of making a stable, nontoxic, and well-transported compound, no animal study system is currently available. As all patients with CDG-Ia have some residual enzymatic activity, it is likely that a complete deletion of the PMM2 gene in the animal would cause embryonic lethality (which is the case in the null PMI mouse ${ }^{83}$ ). The traditional "knockout" technique would therefore not be applicable in the generation of a model system, but rather the creation of an animal with hypomorphic alleles. Another possible arena in CDG therapeutics is direct systemic delivery of PMM. Peptides/proteins can be directly delivered through the cell membrane by adding cell-penetrating peptides, small cationic fragments, to the cargo protein, ${ }^{84}$ and this has proven to work in rodents in vivo. ${ }^{85}$ Whether sufficient PMM would enter cells and be functional with an attached cationic sequence is not known, but this may prove to be the method of choice if the synthetic M1P compounds prove to be impossible.

What positive effects of a working therapy would be reasonable to expect? Man supplementation in CDG-Ib rapidly (weeks to months) corrects or improves the coagulation defects, protein-losing enteropathy, and failure to thrive. Since these are correctable defects in CDG-Ib patients, there is no reason to believe CDG-Ia patients (and possibly other Type I syndromes) would respond differently. Worse are some of the neuronal defectspsychomotor retardation, retinopathy, and muscular hypotonia-not present in CDG-Ib. The underlying damages are probably established already during fetal development and hence postpartal treatment may intervene too late. In one hitherto unpublished report of a CDG-Ib patient, however, epilepsy was noted and this patient showed some improvement in her seizure disorder when she was started on Man. It is still unclear whether the seizures in this patient are related to her metabolic syndrome, but it may suggest that CDG-Ia children with seizures would benefit from M1P-based therapeutics. Another common feature of these children is stroke-like episodes, presumably caused by ineffective anticoagulation. No organized study has been performed to investigate whether common anticoagulants have a positive effect on this symptom, and it would be interesting to see whether a M1P-increasing medication could abolish or improve these episodes. Finally, the cerebellar atrophy/hypoplasia has been a matter of discussion concerning its onset. Some claim that it is a developmentally regulated process, whereas others have published postnatal onset. ${ }^{86}$ It is known, however, that it has a progressive nature ${ }^{87,88}$ and it is thus feasible to speculate that cerebellar function could be partially spared by early interventional therapy.
Acknowledgments: This work was supported by National Institutes of Health Grants R01 DK55615 and R01 DK065091 to H.H.F. as well as a postdoctoral Fellowship from STINT/VR (K2004-99PK-14887-02B) to E.A.E.

\section{REFERENCES}

1. Freeze HH. Disorders in protein glycosylation and potential therapy: tip of an iceberg? J Pediatr 133:593-600, 1998.

2. Haltiwanger RS, Lowe JB. Role of glycosylation in development. Anпи Rev Biochem 73:491-537, 2004.

3. Kornfeld R, Kornfeld S. Assembly of asparagine-linked oligosaccharides. Annu Rev Biochem 54:631-664, 1985.

4. Helenius A, Aebi M. Roles of N-linked glycans in the endoplasmic reticulum. Апnu Rev Biochem 73:1019-1049, 2004.

5. Jaeken J, Carchon H. Congenital disorders of glycosylation: a booming chapter of pediatrics. Curr Opin Pediatr 16:434-439, 2004.

6. Freeze HH, Aebi M. Altered glycan structures: the molecular basis of congenital disorders of glycosylation. Curr Opin Struct Biol 15:490-498, 2005.

7. Marquardt T, Denecke J. Congenital disorders of glycosylation: review of their molecular bases, clinical presentations and specific therapies. Eur J Pediatr 162:359-379, 2003.

8. Jaeken J, Vanderschueren-Lodeweyckx M, Casaer P, Snoeck L, Corbeel L, Eggermont E et al. Familiar psychomotor retardation with markedly fluctuating serum prolactin, FSH and GH levels, partial TBG deficiency, increased serum arylsulphatase A and increased CSF protein: a new syndrome? Pediatr Res 14:179, 1980.

9. Topaz O, Shurman DL, Bergman R, Indelman M, Ratajczak P, Mizrachi $M$ et al. Mutations in GALNT3, encoding a protein involved in O-linked glycosylation, cause familial tumoral calcinosis. Nat Genet 36:579-581, 2004.

10. Frank CG, Grubenmann CE, Eyaid W, Berger EG, Aebi M, Hennet T. Identification and functional analysis of a defect in the human ALG9 gene: definition of congenital disorder of glycosylation type IL. Am J Hum Genet 75:146-150, 2004.

11. Grubenmann CE, Frank CG, Hulsmeier AJ, Schollen E, Matthijs G, Mayatepek E et al. Deficiency of the first mannosylation step in the $\mathrm{N}$-glycosylation pathway causes congenital disorder of glycosylation type Ik. Hum Mol Genet 13:535-542, 2004.

12. Wu X, Rush JS, Karaoglu D, Krasnewich D, Lubinsky MS, Waechter CJ et al. Deficiency of UDP-GlcNAc:dolichol phosphate $\mathrm{N}$-acetylglucosamine-1 phosphate transferase (DPAGT1) causes a novel congenital disorder of glycosylation Type Ij. Hum Mutat 22:144-150, 2003

13. Thiel C, Schwarz M, Peng J, Grzmil M, Hasilik M, Braulke T et al. A new type of congenital disorders of glycosylation (CDG-Ii) provides new insights into the early steps of dolichol-linked oligosaccharide biosynthesis. J Biol Chem 278:22498-22505, 2003.

14. Chantret I, Dancourt J, Dupre T, Delenda C, Bucher S, Vuillaumier-Barrot $\mathrm{S}$ et al. A deficiency in dolichyl-P-glucose: Glc1Man9GlcNAc2-PP-dolichyl alpha3-glucosyltransferase defines a new subtype of congenital disorders of glycosylation. J Biol Chem 278:9962-9971, 2003.

15. Chantret I, Dupre T, Delenda C, Bucher S, Dancourt J, Barnier A et al. Congenital disorders of glycosylation type Ig is defined by a deficiency in dolichyl-P-mannose:Man7GlcNAc2-PP-dolichyl mannosyltransferase. J Biol Chem 277:25815-25822, 2002.

16. Schenk B, Imbach T, Frank CG, Grubenmann CE, Raymond GV, Hurvitz $\mathrm{H}$ et al. MPDU1 mutations underlie a novel human congenital disorder of glycosylation, designated type If. J Clin Invest 108:1687-1695, 2001.

17. Kranz C, Denecke J, Lehrman MA, Ray S, Kienz P, Kreissel G et al. A mutation in the human MPDU1 gene causes congenital disorder of glycosylation type If (CDG-If). J Clin Invest 108:16131619,2001

18. Imbach T, Schenk B, Schollen E, Burda P, Stutz A, Grunewald S et al. Deficiency of dolichol-phosphate-mannose synthase-1 causes congenital disorder of glycosylation type Ie. J Clin Invest 105:233239,2000

19. Körner C, Knauer R, Stephani U, Marquardt T, Lehle L, von Figura K. Carbohydrate deficient glycoprotein syndrome type IV: 
deficiency of dolichyl-P-Man:Man(5)GlcNAc(2)-PP-dolichyl mannosyltransferase. Embo J 18:6816-6822, 1999.

20. Körner C, Knauer R, Holzbach U, Hanefeld F, Lehle L, von Figura K. Carbohydrate-deficient glycoprotein syndrome type V: deficiency of dolichyl-P-Glc:Man9GlcNAc2-PP-dolichyl glucosyltransferase. Proc Natl Acad Sci USA 95:13200-13205, 1998.

21. Niehues R, Hasilik M, Alton G, Korner C, Schiebe-Sukumar M, Koch HG et al. Carbohydrate-deficient glycoprotein syndrome type Ib: phosphomannose isomerase deficiency and mannose therapy. J Clin Invest 101:1414-1420, 1998.

22. Van Schaftingen E, Jaeken J. Phosphomannomutase deficiency is a cause of carbohydrate-deficient glycoprotein syndrome type I. FEBS Lett 377:318-320, 1995.

23. Martinez-Duncker I, Dupre T, Piller V, Piller F, Candelier JJ, Trichet $\mathrm{C}$ et al. Genetic complementation reveals a novel human congenital disorder of glycosylation of type II, due to inactivation of the Golgi CMP-sialic acid transporter. Blood 105:2671-2676, 2005.

24. Wu X, Steet RA, Bohorov O, Bakker J, Newell J, Krieger M et al. Mutation of the COG complex subunit gene COG7 causes a lethal congenital disorder. Nat Med 10:518-523, 2004.

25. Hansske B, Thiel C, Lübke T, Hasilik M, Honing S, Peters V et al. Deficiency of UDP-galactose: $N$-acetylglucosamine beta-1,4-galactosyltransferase I causes the congenital disorder of glycosylation type IId. J Clin Invest 109:725-733, 2002.

26. Lübke T, Marquardt T, Etzioni A, Hartmann E, von Figura K, Körner C. Complementation cloning identifies CDG-IIc, a new type of congenital disorders of glycosylation, as a GDP-fucose transporter deficiency. Nat Genet 28:73-76, 2001.

27. De Praeter CM, Gerwig GJ, Bause E, Nuytinck LK, Vliegenthart $\mathrm{JF}$, Breuer $\mathrm{W}$ et al. A novel disorder caused by defective biosynthesis of N-linked oligosaccharides due to glucosidase I deficiency. Am J Hum Genet 66:1744-1756, 2000.

28. Charuk JH, Tan J, Bernardini M, Haddad S, Reithmeier RA, Jaeken J et al. Carbohydrate-deficient glycoprotein syndrome type II: an autosomal recessive $N$-acetylglucosaminyltransferase II deficiency different from typical hereditary erythroblastic multinuclearity, with a positive acidified-serum lysis test (HEMPAS). Eur J Biochem 230:797-805, 1995.

29. Stibler H, Jaeken J. Carbohydrate deficient serum transferrin in a new systemic hereditary syndrome. Arch Dis Child 65:107-111, 1990.

30. Lacey JM, Bergen HR, Magera MJ, Naylor S, O’Brien JF. Rapid determination of transferrin isoforms by immunoaffinity liquid chromatography and electrospray mass spectrometry. Clin Chem 47:513-518, 2001.

31. Helander A, Bergstrom J, Freeze HH. Testing for congenital disorders of glycosylation by HPLC measurement of serum transferrin glycoforms. Clin Chem 50:954-958, 2004.

32. Carchon HA, Chevigne R, Falmagne JB, Jaeken J. Diagnosis of congenital disorders of glycosylation by capillary zone electrophoresis of serum transferrin. Clin Chem 50:101-111, 2004.

33. Charlwood J, Clayton P, Keir G, Mian N, Winchester B. Defective galactosylation of serum transferrin in galactosemia. Glycobiology 8:351-357, 1998.

34. Adamowicz M, Pronicka E. Carbohydrate deficient glycoprotein syndrome-like transferrin isoelectric focusing pattern in untreated fructosaemia. Eur J Pediatr 155:347-348, 1996.

35. Stibler H, Borg S, Joustra M. Micro anion exchange chromatography of carbohydrate-deficient transferrin in serum in relation to alcohol consumption (Swedish Patent 8400587-5). Alcohol Clin Exp Res 10:535-544, 1986.

36. Callewaert N, Van Vlierberghe H, Van Hecke A, Laroy W, Delanghe J, Contreras R. Noninvasive diagnosis of liver cirrhosis using DNA sequencer-based total serum protein glycomics. Nat Med 10:429-434, 2004.

37. Hansen SH, Frank SR, Casanova JE. Cloning and characterization of human phosphomannomutase, a mammalian homologue of yeast SEC53. Glycobiology 7:829-834, 1997.

38. Kjaergaard S, Schwartz M, Skovby F. Congenital disorder of glycosylation type Ia (CDG-Ia): phenotypic spectrum of the R141H/ F119L genotype. Arch Dis Child 85:236-239, 2001.

39. Miossec-Chauvet E, Mikaeloff Y, Heron D, Merzoug V, Cormier-
Daire V, de Lonlay P et al. Neurological presentation in pediatric patients with congenital disorders of glycosylation type Ia. Neuropediatrics 34:1-6, 2003.

40. Grunewald S, Schollen E, Van Schaftingen E, Jaeken J, Matthijs G. High residual activity of PMM2 in patients' fibroblasts: possible pitfall in the diagnosis of CDG-Ia (phosphomannomutase deficiency). Am J Hum Genet 68:347-354, 2001.

41. Westphal V, Peterson S, Patterson M, Tournay A, Blumenthal A, Treacy EP et al. Functional significance of PMM2 mutations in mildly affected patients with congenital disorders of glycosylation Ia. Genet Med 3:393-398, 2001.

42. Di Rocco M, Barone R, Adami A, Burlina A, Carrozzi M, DionisiVici $\mathrm{C}$ et al. Carbohydrate-deficient glycoprotein syndromes: the Italian experience. J Inherit Metab Dis 23:391-395, 2000.

43. Bohles H, Sewell AA, Gebhardt B, Reinecke-Luthge A, Kloppel G, Marquardt T. Hyperinsulinaemic hypoglycaemia-leading symptom in a patient with congenital disorder of glycosylation Ia (phosphomannomutase deficiency). J Inherit Metab Dis 24:858862, 2001.

44. Damen G, de Klerk H, Huijmans J, den Hollander J, Sinaasappel M. Gastrointestinal and other clinical manifestations in 17 children with congenital disorders of glycosylation type Ia, Ib, and Ic. J Pediatr Gastroenterol Nutr 38:282-287, 2004.

45. Marquardt T, Hulskamp G, Gehrmann J, Debus V, Harms E, Kehl HG. Severe transient myocardial ischaemia caused by hypertrophic cardiomyopathy in a patient with congenital disorder of glycosylation type Ia. Eur J Pediatr 161:524-527, 2002.

46. Albach C, Klein RA, Schmitz B. Do rodent and human brains have different N-glycosylation patterns? Biol Chem 382:187-194, 2001.

47. Aronica E, van Kempen AA, van der Heide M, Poll-The BT, van Slooten HJ, Troost D et al. Congenital disorder of glycosylation type Ia: a clinicopathological report of a newborn infant with cerebellar pathology. Acta Neuropathol (Berl) 109:433-442, 2005.

48. Sun L, Eklund EA, Van Hove JL, Freeze HH, Thomas JA. Clinical and molecular characterization of the first adult congenital disorder of glycosylation (CDG) type Ic patient. Am J Med Genet A 137: 22-26, 2005.

49. Denecke J, Kranz C, Kemming D, Koch HG, Marquardt T. An activated $5^{\prime}$ cryptic splice site in the human ALG3 gene generates a premature termination codon insensitive to nonsense-mediated mRNA decay in a new case of congenital disorder of glycosylation type Id (CDG-Id). Hum Mutat 23:477-486, 2004.

50. Schollen E, Grunewald S, Keldermans L, Albrecht B, Korner C, Matthijs G. CDG-Id caused by homozygosity for an ALG3 mutation due to segmental maternal isodisomy UPD3(q21.3-qter). Eur J Med Genet 48:153-158, 2005.

51. Sun L, Eklund EA, Chung WK, Wang C, Cohen J, Freeze HH. Congenital disorder of glycosylation id presenting with hyperinsulinemic hypoglycemia and islet cell hyperplasia. J Clin Endocrinol Metab 90:4371-4375, 2005.

52. Garcia-Silva MT, Matthijs G, Schollen E, Cabrera JC, Sanchez del Pozo J, Marti Herreros M et al. Congenital disorder of glycosylation (CDG) type Ie: a new patient. J Inherit Metab Dis 27:591600, 2004.

53. Kim S, Westphal V, Srikrishna G, Mehta DP, Peterson S, Filiano $\mathrm{J}$ et al. Dolichol phosphate mannose synthase (DPM1) mutations define congenital disorder of glycosylation Ie (CDG-Ie). J Clin Invest 105:191-198, 2000.

54. Eklund EA, Newell JW, Sun L, Seo NS, Alper G, Willert J et al. Molecular and clinical description of the first US patients with congenital disorder of glycosylation Ig. Mol Genet Metab 84:2531, 2005

55. Eklund EA, Sun L, Westphal V, Northorp JL, Freeze HH, Scaglia F. Congenital disorder of glycosylation (CDG)-Ih associated with a severe hepato-intestinal phenotype and evolving central nervous system pathology. J Pediatr 147:847-850, 2005.

56. Schollen E, Frank CG, Keldermans L, Reyntjens R, Grubenmann $\mathrm{CE}$, Clayton PT et al. Clinical and molecular features of three patients with congenital disorders of glycosylation type Ih (CDGIh) (ALG8 deficiency). J Med Genet 41:550-556, 2004.

57. Schwarz M, Thiel C, Lubbehusen J, Dorland B, de Koning T, von Figura K et al. Deficiency of GDP-Man:GlcNAc2-PP-dolichol 
mannosyltransferase causes congenital disorder of glycosylation type Ik. Am J Hum Genet 74:472-481, 2004.

58. Kranz C, Denecke J, Lehle L, Sohlbach K, Jeske S, Meinhardt F et al. Congenital disorder of glycosylation type Ik (CDG-Ik): a defect of mannosyltransferase I. Am J Hum Genet 74:545-551, 2004.

59. Gao N, Lehrman MA. Analyses of dolichol pyrophosphate-linked oligosaccharides in cell cultures and tissues by fluorophore-assisted carbohydrate electrophoresis. Glycobiology 12:353-360, 2002.

60. Weinstein M, Schollen E, Matthijs G, Neupert C, Hennet T, Grubenmann CE et al. CDG-IL: an infant with a novel mutation in the ALG9 gene and additional phenotypic features. Am J Med Genet A 136:194-197, 2005.

61. Tan J, Dunn J, Jaeken J, Schachter H. Mutations in the MGAT2 gene controlling complex $\mathrm{N}$-glycan synthesis cause carbohydratedeficient glycoprotein syndrome type II, an autosomal recessive disease with defective brain development. Am J Hum Genet 59: 810-817, 1996.

62. Tan J, D'Agostaro AF, Bendiak B, Reck F, Sarkar M, Squire JA et al. The human UDP- $N$-acetylglucosamine: alpha-6-D-mannosidebeta-1,2- $N$-acetylglucosaminyltransferase II gene (MGAT2): Cloning of genomic DNA, localization to chromosome 14q21, expression in insect cells and purification of the recombinant protein. Eur J Biochem 231:317-328, 1995.

63. Wang Y, Schachter H, Marth JD. Mice with a homozygous deletion of the Mgat2 gene encoding UDP- $N$-acetylglucosamine:alpha6-D-mannoside beta1,2- $N$-acetylglucosaminyltransferase II: a model for congenital disorder of glycosylation type IIa. Biochim Biophys Acta 1573:301-311, 2002.

64. Van Geet C, Jaeken J, Freson K, Lenaerts T, Arnout J, Vermylen $\mathrm{J}$ et al. Congenital disorders of glycosylation type Ia and IIa are associated with different primary haemostatic complications. J Inherit Metab Dis 24:477-492, 2001.

65. Marquardt T, Luhn K, Srikrishna G, Freeze HH, Harms E, Vestweber D. Correction of leukocyte adhesion deficiency type II with oral fucose. Blood 94:3976-3985, 1999.

66. Kotani N, Asano M, Iwakura Y, Takasaki S. Knockout of mouse beta 1,4-galactosyltransferase-1 gene results in a dramatic shift of outer chain moieties of $\mathrm{N}$-glycans from type 2 to type 1 chains in hepatic membrane and plasma glycoproteins. Biochem J 357:827834, 2001.

67. Ungar D, Oka T, Brittle EE, Vasile E, Lupashin VV, Chatterton JE et al. Characterization of a mammalian Golgi-localized protein complex, COG, that is required for normal Golgi morphology and function. J Cell Biol 157:405-415, 2002.

68. Spaapen LJ, Bakker JA, van der Meer SB, Sijstermans HJ, Steet RA, Wevers RA et al. Clinical and biochemical presentation of siblings with COG-7 deficiency, a lethal multiple O- and N-glycosylation disorder. J Inherit Metab Dis 28:707-714, 2005.

69. Kingsley DM, Kozarsky KF, Segal M, Krieger M. Three types of low density lipoprotein receptor-deficient mutant have pleiotropic defects in the synthesis of N-linked, O-linked, and lipid-linked carbohydrate chains. J Cell Biol 102:1576-1585, 1986.

70. Matthijs G, Foulquier F, Vasile E, Ungar D, Krieger M, Annaert W. Deficiencies in the different subunits of the Conserved Oligomeric Golgi (COG) complex define a novel group of congenital disorders of glycosylation. Abstract at the 2005 ASHG meeting, Salt Lake City, UT.

71. Willig TB, Breton-Gorius J, Elbim C, Mignotte V, Kaplan C, Mollicone R et al. Macrothrombocytopenia with abnormal demarcation membranes in megakaryocytes and neutropenia with a com- plete lack of sialyl-Lewis- $\mathrm{X}$ antigen in leukocytes: a new syndrome? Blood 97:826-828, 2001.

72. Westphal V, Kjaergaard S, Davis JA, Peterson SM, Skovby F, Freeze HH. Genetic and metabolic analysis of the first adult with congenital disorder of glycosylation type Ib: long-term outcome and effects of mannose supplementation. Mol Genet Metab 73:77$85,2001$.

73. Harms HK, Zimmer KP, Kurnik K, Bertele-Harms RM, Weidinger $\mathrm{S}$, Reiter K. Oral mannose therapy persistently corrects the severe clinical symptoms and biochemical abnormalities of phosphomannose isomerase deficiency. Acta Paediatr 91:1065-1072, 2002.

74. Etzioni A, Tonetti M. Fucose supplementation in leukocyte adhesion deficiency type II. Blood 95:3641-3643, 2000.

75. Etzioni A, Sturla L, Antonellis A, Green ED, Gershoni-Baruch R, Berninsone PM et al. Leukocyte adhesion deficiency (LAD) type II/carbohydrate deficient glycoprotein (CDG) IIc founder effect and genotype/phenotype correlation. Am J Med Genet 110:131135, 2002.

76. Panneerselvam K, Freeze HH. Mannose corrects altered N-glycosylation in carbohydrate-deficient glycoprotein syndrome fibroblasts. J Clin Invest 97:1478-1487, 1996.

77. Mayatepek E, Kohlmuller D. Mannose supplementation in carbohydrate-deficient glycoprotein syndrome type I and phosphomannomutase deficiency. Eur J Pediatr 157:605-606, 1998.

78. Mayatepek E, Schroder M, Kohlmuller D, Bieger WP, Nutzenadel W. Continuous mannose infusion in carbohydrate-deficient glycoprotein syndrome type I. Acta Paediatr 86:1138-1140, 1997.

79. Kjaergaard S, Kristiansson B, Stibler H, Freeze HH, Schwartz M, Martinsson $\mathrm{T}$ et al. Failure of short-term mannose therapy of patients with carbohydrate-deficient glycoprotein syndrome type 1A. Acta Paediatr 87:884-888, 1998.

80. Eklund EA, Merbouh N, Ichikawa M, Nishikawa A, Clima JM, Dorman JA et al. Hydrophobic Man-1-P derivatives correct abnormal glycosylation in Type I congenital disorder of glycosylation fibroblasts. Glycobiology 15:1084-1093, 2005.

81. Muus U, Kranz C, Marquardt T, Meier C. cycloSaligenyl-mannose-1-monophosphates as a new strategy in CDG-Ia therapy: hydrolysis, mechanistic insights and biological activity. Eur J Org Chem 2004:1228-1235, 2004.

82. Rutschow S, Thiem J, Kranz C, Marquardt T. Membrane-permeant derivatives of mannose-1-phosphate. Bioorg Med Chem 10:40434049, 2002.

83. Derossi C, Bode L, Eklund EA, Zhang F, Davis JA, Westphal V et al. Ablation of mouse phosphomannose isomerase (Mpi) causes mannose-6-phosphate accumulation, toxicity, and embryonic lethality. J Biol Chem December 8, 2005 [Epub].

84. Snyder EL, Dowdy SF. Cell penetrating peptides in drug delivery. Pharm Res 21:389-393, 2004.

85. Schwarze SR, Ho A, Vocero-Akbani A, Dowdy SF. In vivo protein transduction: delivery of a biologically active protein into the mouse. Science 285:1569-1572, 1999.

86. Drouin-Garraud V, Belgrand M, Grunewald S, Seta N, Dacher JN, Henocq A et al. Neurological presentation of a congenital disorder of glycosylation CDG-Ia: implications for diagnosis and genetic counseling. Am J Med Genet 101:46-49, 2001.

87. Akaboshi S, Ohno K, Takeshita K. Neuroradiological findings in the carbohydrate-deficient glycoprotein syndrome. Neuroradiology 37:491-495, 1995

88. Ohno K, Yuasa I, Akaboshi S, Itoh M, Yoshida K, Ehara H et al. The carbohydrate deficient glycoprotein syndrome in three Japanese children. Brain Dev 14:30-35, 1992. 